\title{
Study of IE Teacher-Student Interaction Pattern Based on Informational Education Environment
}

\author{
Jijun Xiao ${ }^{1, a,{ }^{*}}$, Shu Ou ${ }^{2, b}$ \\ ${ }^{1,2}$ Guilin University of Electronic Technology, Guilin, China \\ axyd312@qq.com, ${ }^{\text {b2 } 277960865 @ q q . c o m ~}$
}

\begin{abstract}
Keywords: Teacher-Student Interaction Pattern, Informational Environment, Industrial Engineering. Abstract. With the continuous development of industrial engineering (IE) discipline in universities, it is essential to accelerate the construction of IE disciplines, educational concept, evaluation and specification of teaching level against the new background of economic and informational globalization. The teaching of IE can not be limited to theoretical aspect in consideration of its integrity and practicality. If students study the principal of IE individually, the grasp of theoretical system while the lack of practical experience and comprehension of the enterprises' development contrarily means that universities almost fail to cultivate real talents. The design of IE curriculum is based on the actual needs of engineering, which aims to develop students' ability to solve practical problems by using the expertise knowledge and basic attainment comprehensively. In order to enhance the capacity of students in using IE knowledge integrally, the communication based on information platform is not only the embodiment of interactive pattern between teachers and students in universities, but also an effective channel to improve the independence of self-improvement, the level of teacher-student interaction and the quality of teaching constantly.
\end{abstract}

\section{Introduction}

Nowadays enterprises are inclined to examine the comprehensive quality of employee much further. This comprehensive quality can be visualized as the potentiality to identify problems, submit questions, solve problems and form original opinions precisely by using possessed knowledge and abilities. In the university, students should pay more attention to the fundamental quality, and the university ought to offer students an independent development environment relatively. According to the differences of individuals, the cultivation of learners' personality and practical talents deserve to be stressed.

The objective of IE cultivation focus on several aspects, besides the obtainment of solid theory in mathematics, physics and social science, the capacity about predicting and evaluating certain engineering system on account of vast knowledge and analysis methods also should be classified as talents assessment standards. In addition to traditional industrial sector, the application of IE technology even extends to construction, transport, banks, hospitals and other emerging departments. There is no doubt that the effective utilization of IE will bring significant economic and social benefits to various industries. However, the urgent issue is widely recognized as finding proper approach to convert the knowledge obtained in university into practical ability, which coincides with the diversified demand of various industries straightly.

\section{Construction of IE teacher-student interaction pattern}

Every university experienced its unique evolution in construction and emerged distinctive subjects, the communication pattern between teachers and students should be treated specifically ${ }^{[1,4]}$. The purpose of founding experimental courses and constructing information resources platform is to deepen students' understanding for basic concepts and application of IE technology.

Comprehensive practicality is accepted as one of the outstanding feature in IE subject. However, the experimental teaching of IE in our country is relatively late and lack available unified model. So the focal point to strengthen the professional practice ability is the experimental system construction 
of teaching course [5]. The experimental teaching had better cover major IE sectors, such as basic IE, human factors engineering, production planning and control, quality management, engineering economics, management information systems, logistics engineering, modern manufacturing systems, system analysis and design and so on. With the entire framework, the cognition and simulation of whole production management in enterprises can be strengthened consequently. Excellent platform integrating information resource and experimental research can consolidate the teacher-student interaction, cultivate team capacity in tackling challenge and combine experimental teaching with theoretical teaching content.

Information technology has been applied in the university education recently, students and teachers can use the network platform to achieve interactive communication. The brief framework is shown in Fig.1, which includes ample content like experiments, teaching and subdivided modules. Teaching materials module stores teaching courseware information. Program management module records experimental and teaching plan. Experiment management module allows teachers to grasp the progress of experiments. Experimental recording module stores students' experimental results and reports. The modules mentioned above provide teachers with the assistance in supervision. Students can download teaching, laboratory information voluntarily before the lessons and experiments. After the end of experiment, teachers can evaluate results and answer questions through the uploaded experiment data and test reports in experiment management module.

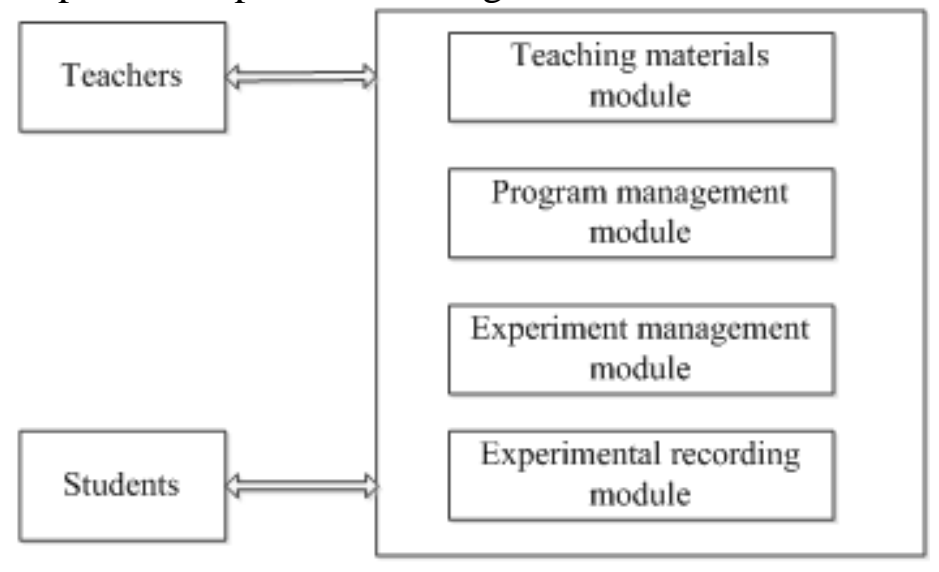

Fig.1.Interactive communication on network platform

In terms of professional training program, university can improve the proportion of optional courses and experimental courses, so as to detect students' proficiency in professional theory and raise basic IE skills. Meanwhile, university should encourage students to participate in extracurricular activities like technology lecture, science competition and social practice. In order to strengthen practical training, it would be best to bring enterprise production practice into teaching programs. With the combination of theory and reality, IE students will promote the strength in discovering problem and optimizing production situation with the aid of specialized knowledge.

\section{The implementation of IE teacher-student interaction pattern on the network platform}

Ensure the systematical connection of experiment and teaching knowledge. Ultimately, the network platform can be used to realize the dynamic, real-time update of teaching information. And even the teaching feedback from students can be received quickly, which gets the network teaching and network experiment modified continuously.

By the application of network platform, teaching activities can benefit from the abundant multimedia interaction and make the transferring of knowledge more efficient and vivid. Even without paper recording, teaching guidance also can realize the high degree of resource share. It is apparent that the teaching requirement and time saving will be optimized simultaneously. Compared to traditional teaching pattern, the network platform may create a better operational feeling, allow audience to find the weak point quickly and meet students' need about professional knowledge and 
practice at any time. As shown in Fig.2, the implement of network technology in teaching platform can be regarded as the innovation in experimental teaching and course design that not only step up technological methods, but also reconcile the practice process, theory teaching, network experiment and comprehensive training.

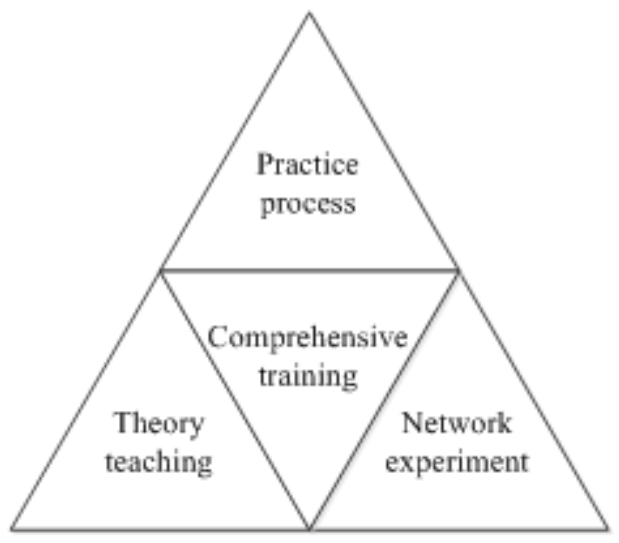

Fig.2.Network teaching system

\section{Standardized management of IE teacher-student interaction pattern}

During the university teaching activities, the interaction between teachers and students is definitely a kind of communication behavior, which equals to the transferring and understanding of knowledge. The first point is to emphasize the transmission of meaning, there will be no communication until information or view is expressed coherently. But more importantly, the communication also includes the understanding of information [3]. Therefore, the realization of correct presentation and understanding is the necessary condition for excellent teacher-student interaction. The orientation that students master and apply knowledge should be the teaching goal in the course of cultivation, and teaching information should be compiled properly by the application of appropriate media. It is essential that students can realize the importance of major courses, understand the meaning after receiving teaching information and make corresponding response. It will achieve no complete information interaction process, only when the above process is already finished. With the aid of educational information platform, the function of media can be utilized effectively and teaching information compilation also can get simplified in the process of communication. But in the entire process of communication, it is known that the presence of noise interference is inevitable. As long as any items cause disturbance to the understanding of meaning, they can be defined as information noise, so there will exist the distortion of teaching information between sender and receiver, the information transmitted from teachers to students appears a decreasing trend. As shown in Fig.3, the basic situation is just like a funnel model.

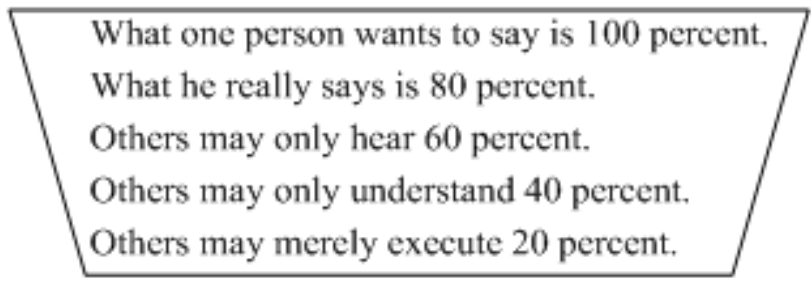

Fig.3. Communication funnel model

It is precise that the prompt monitoring and feedback play the key role in the teaching interaction, considering the continuous decline in the process of information transferring. Teachers have responsibility to check the students' academic performance regularly and listen to the feedback information from students to find out their shortcomings. Students should put themselves in a correct position, pay attention to knowledge achievement and respond their feelings actively to teachers. 
After constructing the interaction patterns in the informational education environment, the standardization and habituation should be used to reduce errors, inefficiency and misunderstanding in communication. The sustainable development of interactive pattern can be strengthened with overall good interactive atmosphere. The dominant trait of industrial engineering is practicality, so the cultivation of students' practical ability becomes particularly important, the experiment and practice own an incomparable position in the industrial engineering teaching further. It's because of practice-oriented, the impartment of industrial engineering knowledge is a delegate in fishing methods. After accepting knowledge and mastering the basic, standardized methods and work measurement theory, students should be provided with the ability in thinking and conducting practice by theory guidance.

\section{Summary}

It might sound like corny that we need to elevate perceptual knowledge to rational knowledge. However, students usually learn lots of theoretical knowledge before starting experiment, cognitive practice and graduation practice in the current university education. There are professional instructors and a systemic curriculum in university, which provides students adequate four years to learn and understand previous theoretical experience better. People always define it as one of the ways to effectively obtain professional knowledge. But considering the dialectical relationship of practice and understanding, practice acting as the source, motivation, purpose and destination of understanding requires students to master the subject knowledge and strengthen the practical ability. Relying on the standardized experiment, practice system, interactive information platform, practical activity and so on, students' potentiality to solve practical problems may achieve a qualitative leap.

\section{Acknowledgements}

This research was partly supported by the Education and Teaching Reform Project of GUET (Grant NO. JGB201413) and Innovation Project of Guangxi Graduate Education(Grant NO. JGY2015066)

\section{References}

[1] Ye Z A, Pang L. On the Basic Course of the Formation of Teacher-student Interaction Pattern, Educational Research, vol.349, pp.78-82, 2009.

[2] Hashamdar M. The Teacher-Student Communication Pattern: A Need to Follow? Brain Broad Research in Artificial Intelligence \& Neuroscience, vol.02, pp.29-35, 2012.

[3] Hsueh-Yung K, Wang D H, Department I E, et al. Maker/Hacker Movement and the Global Science \& Technology Education. Modern Educational Technology, vol.25, pp.12-17, 2015.

[4] Thurston L D. Polytechnic helps solve local industry's need for engineering talent. Caribbean Business, vol.36, pp. 14-27, 2008.

[5] Terashima, K. Cultivation of Leader Talent by MOT Oriented Technology and Science Education by Collaboration between University and Industry. Journal of Japan Foundry Engineering Society, vol.81, pp.187-188, 2009. 